\title{
FUI UM TRADUTOR OU UM TRAIDOR? TRADUÇÃO DE UMA HISTÓRIA NEOZELANDESA RIMADA E UMA PEQUENA REFLEXÃO SOBRE TRADUÇÃO LITERÁRIA
}

\author{
DID I ACT LIKE A TRANSLATOR OR A TRAITOR? \\ TRANSLATION OF A NEW ZEALANDER RHYTHMIC HISTORY AND BRIEF \\ CONSIDERATIONS ON LITERARY TRANSLATION
}

Rogério Migliorini ${ }^{1}$

Aqui, apresento a tradução da história rimada chamada Quaky Cat de autoria de uma autora neozelandesa e faço uma pequena reflexão sobre este tipo de tradução. Meu texto não apresenta nenhuma novidade para tradutores de obras literárias e artísticas ou para estudiosos da questão. Todavia, minha intenção foi apenas obter alguma satisfação como tradutor/artista e compartilhá-la com possíveis leitores, após uma série de experiências bastante desagradáveis com a tradução de textos técnicos e acadêmicos.

Antes de começar, também vale dizer que uma amiga chamou minha atenção para o fato de que eu traduzo de um inglês que não é o original da Inglaterra, para o português que não é o original de Portugal, baseio o título em um ditado italiano e meu sobrenome é também italiano. Este comentário me fez lembrar do nosso mundo tão globalizado. Uma questão sobre a qual não vou me deter aqui.

Sobre isso, basta dizer que, em 1979, quando eu tinha 16 anos, embora o mundo já fosse globalizado, havia pouquíssimas informações sobre a Nova Zelândia no Brasil. Tanto que apenas seis meses antes de eu ir para lá como intercambista, eu fiquei sabendo que aquele era um país anglófono. Até aí, não havia problemas, pois eu estudava inglês em uma escola de línguas. Entretanto, para não fazer uma prova, eu me desliguei dela assim que soube da mudança próxima. Afinal, eu iria mesmo para uma escola melhor dali a um semestre. Assim, as pessoas das ruas, as famílias com que eu morei e meus colegas de high school foram meus principais mestres. Ah, não posso esquecer de colocar nessa lista o meu excelente professor de inglês neozelandês e os vários livros da biblioteca da escola.

Voltando ao Brasil fiz um curso ou outro de inglês bem mais avançado, tradução e literatura inglesa e americana, porém nunca me interessei pelo estudo formal da língua ou em trabalhar com ela. Assim, apesar de eu ter dado aulas de inglês como segunda língua (ESL) e trabalhado por anos fazendo traduções técnicas, não me considero nem professor de inglês nem tradutor.

Isso também porque no início eu evitava traduzi-las. Eu me lembro da minha professora do colegial no Brasil dizendo que isso iria prejudicar nosso aprendizado da língua. Além disso, quando eu voltei de Aotearoa-Nova Zelândia eu não conseguia fazer a conexão entre as línguas direito. É como se eu tivesse divisões no cérebro que não se intercomunicavam e cada língua estivesse em uma delas.

No entanto, línguas me atraem ou, melhor dizendo, as formas de arte a elas ligadas. O meu primeiro contato com Quaky Cat foi em um programa de contação de histórias para crianças na Rádio Nacional da Nova Zelândia (RZN), chamado Storytime. Como as histórias narradas me encantam, meu interesse foi imediato. Além disso, aquela era uma bela obra literária infantil, extremamente sensível, com sonoridade e ritmo altamente sedutores e tratava de uma catástrofe local, um grande terremoto. Somava-se a isso, o som das palavras, a particularidade do sotaque, a riqueza da entonação, enfim, a música da fala somada à perfeição do texto. Por fim, tudo cuja

\footnotetext{
${ }^{1}$ Artista independente, São Paulo, SP, Brasil.
} 
origem é aquela região do mundo, tão distante e ainda relativamente desconhecida para nós, me interessa muito. Então, resolvi traduzir o livro Quaky Cat e apresentá-lo a um grupo literário que se reúne informalmente de dois em dois meses, do qual ainda participo.

Como eu não tinha o texto escrito, entrei em contato com a autora, Diana Noonan, que o enviou para mim. Eu considero que esse passo também fez parte do processo de tradução, porque pediu um tipo de utilização da língua mais relacionada com a minha vivência, isto é, com o aprendizado da língua estrangeira voltado para a necessidade de comunicação com as pessoas daquele país. Nesse sentido, se eu tivesse ido para qualquer outro país, eu teria aprendido a língua local mesmo se eu nunca fosse usá-la novamente. Ter aprendido inglês por acaso e nunca almejado trabalhar a língua, é mais uma razão para eu não me considerar um professor de inglês ou um tradutor.

Bem, digressão feita, o grupo literário não só recebeu muito bem o trabalho como, para minha surpresa, sugeriu a sua publicação e até me ajudou em uma primeira tentativa de fazêla, mas que não vingou, por diversas razões. No entanto, me apontou algo importantíssimo que eu não tinha percebido ainda. Mesmo desconhecendo terremotos no Brasil, somos bem familiarizados com deslizamentos de terra e enchentes que afetam não só pessoas de todas as idades, como também animais, plantas e o próprio ambiente. São catástrofes que alteram a topografia, causam traumas por provocarem destruição, morte, perdas materiais e afetivas. Pouco tempo antes da apresentação do texto ao referido grupo literário, havia ocorrido o deslizamento de terra na região serrana do estado do Rio de Janeiro, o rompimento da barragem de Mariana e o consequente desastre ambiental ao longo da Bacia Hidrográfica do Rio Doce. Duas semanas depois, a barragem de Brumadinho se rompeu. Nos três acontecimentos, 1.000 pessoas morreram e mais de 15.000 ficaram desalojadas e desabrigadas. Com isso, Quaky Cat, bem como a observação do grupo, adquiriram tons premonitórios.

Quanto à tradução dessa história rimada, eu nunca fiz qualquer esforço para escolher palavras em português com o mesmo ritmo e som das palavras em inglês. Isso simplesmente porque línguas diferentes quase nunca têm os mesmos sons. A tradução do título é um exemplo claro disso. Suas palavras quaky e cat formam um par por aliteração, outros tipos de consonâncias e comprimento - poetas e estudiosos saberão falar disso com muito mais propriedade do que eu. Portanto, "gato do terremoto" ou algo assim não faria jus ao original. Assim, por aliteração, outros tipos de consonância e comprimento, eu também fiz um par com duas palavras em português. Para isso, traduzi o nome do gato e usei o adjetivo "trêmulo". Dessa forma, ao traduzir o título por "Tigre Trêmulo", eu não usei uma única palavra equivalente àquelas encontradas no texto fonte. Mesmo assim, creio ter atingido o resultado desejado.

Mas talvez esteja aí a diferença entre tradução técnica e literária. Em tradução, não se esquece da obra matriz; mas, na última, além de ser fiel ao significado exato das palavras, o tradutor precisa sintonizar-se com a obra e acompanhar a criatividade do autor. Esse tipo de tradução não é menos trabalhosa. Ao contrário. Contudo, por mais árdua que tenha sido, sem dúvida alguma, esse foi um dos trabalhos que eu tive mais prazer em fazer e também foi um dos melhores, em termos de resultado.

Aliás, muitas vezes os melhores resultados vêm do divertido, do prazeroso e daquilo que provoca um saudável relaxamento mental. Aprendi isso em uma aula de redação do colegial por volta da época em que fui para a Nova Zelândia. Preciso voltar a lembrar disso com mais frequência.

Bem, mas diante do exposto acima eu não pude evitar o autoexame e a questão: eu fui um tradutor ou um traidor? Sim, tal pergunta me parece bastante pertinente, pois eu posso ter negligenciado muitas coisas, de propósito. Entretanto, creio não ter feito pouco caso da intenção da autora e, muito menos, da sua obra.

Eis aí a tradução. Julguem por si mesmos. 
Para apreciá-la melhor, sugiro que junto com a leitura, ouçam a narração original no link https://www.radionz.co.nz/collections/storytime-treasure-chest/audio/2516107/quaky-cat-bydiana-noonan.

\begin{tabular}{|c|c|}
\hline $\begin{array}{l}\text { Quaky Cat } \\
\text { by Diana Noonan }\end{array}$ & $\begin{array}{l}\text { Tigre Trêmulo } \\
\text { Trad. de R Migliorini }\end{array}$ \\
\hline $\begin{array}{l}\text { On a cold Christchurch morning, while the } \\
\text { city was sleeping, } \\
\text { before the birds roused him with twitters and } \\
\text { cheeping, } \\
\text { curled up on the end of his friend Emma's } \\
\text { bed, } \\
\text { Tiger woke with a start ... and a feeling of } \\
\text { dread. }\end{array}$ & $\begin{array}{l}\text { Numa manhã fria em Christchurch, com o } \\
\text { povo ainda alheio, } \\
\text { e antes dos pássaros o despertarem com } \\
\text { trinados e gorjeios, } \\
\text { Tigre, que dormia enrolado aos pés do leito } \\
\text { de Emma, } \\
\text { acordou de um salto... e com um aperto no } \\
\text { peito. }\end{array}$ \\
\hline $\begin{array}{l}\text { He twitched his long whiskers and sniffed at } \\
\text { the air. } \\
\text { Danger was close, but what was it - and } \\
\text { where? } \\
\text { Then a voice in his head, one he'd not heard } \\
\text { before, } \\
\text { shouted, Run for your life, Tiger! Make for } \\
\text { the door! } \\
\text { Tiger fled from the house with a leap and a bound } \\
\text { as, louder than thunder, from deep } \\
\text { underground, } \\
\text { came a roar and a shudder and terrible } \\
\text { shaking! } \\
\text { Around him, the city was rolling and } \\
\text { quaking. }\end{array}$ & $\begin{array}{l}\text { Fremiu seus longos bigodes e cheirou o ar. } \\
\text { Pressentiu perigo próximo. Mas o quê - e } \\
\text { onde? } \\
\text { Então, uma voz desconhecida, gritou dentro } \\
\text { de si, } \\
\text { Depressa, Tigre! Salve-se! Saia já daí. } \\
\text { Em carreira desabalada o bichano fugiu da } \\
\text { casa } \\
\text { enquanto, mais alto que um trovão, do fundo } \\
\text { da terra, } \\
\text { subia um ribombo, um ronco e um pavoroso } \\
\text { tremor! } \\
\text { À sua volta, a cidade sacudia e caía. }\end{array}$ \\
\hline $\begin{array}{l}\text { He raced up the path as it buckled and bent, } \\
\text { as the mailbox swayed - even faster he went! } \\
\text { Round swings that were squeaking and } \\
\text { roundabouts creaking, } \\
\text { the shuddering school with its swimming } \\
\text { pool leaking. }\end{array}$ & $\begin{array}{l}\text { Correu pela entrada da garagem que arcava } \\
\text { e arqueava, quanto mais ela corcoveava - } \\
\text { mais ele se apressava! } \\
\text { Voou por entre balanços que rangiam e } \\
\text { gangorras que gemiam, } \\
\text { e pela escola já abalada cuja piscina vazava. }\end{array}$ \\
\hline $\begin{array}{l}\text { Over the Avon on bridges that wiggled, } \\
\text { he shot through the city on footpaths that } \\
\text { jiggled. } \\
\text { Above him, the pigeons fled tumbling } \\
\text { perches } \\
\text { and dodged round the spires of crumbling } \\
\text { churches. }\end{array}$ & $\begin{array}{l}\text { Pelas pontes que oscilavam sobre o Avon } \\
\text { disparou, } \\
\text { por calçadas balouçantes chispou. } \\
\text { Sobre ele, pombos abandonavam poleiros a } \\
\text { despencar e se desviavam de pináculos de } \\
\text { igrejas a tombar. }\end{array}$ \\
\hline
\end{tabular}


The whole city rocked. It reeled and it rolled.

All by themselves the cathedral bells tolled. With no place to hide and no time to spare, Tiger shot up a quivering tree in the square.

When he'd clawed his way up to the top, he looked down ...

and saw, in the tree, half the cats in the town!

Below them bricks crashed, chimneys fell, shops caved in!

Sirens were wailing - and the cats joined the din.

As the sun rose that morning, the world looked with pity

at the folk on the streets of their tumbleddown city.

In the tree, Tiger shivered, he was cold and forlorn.

Where was his Emma, in this muddled-up dawn?

Afraid, the cats huddled, with hisses and wails, with whiskers cast down and sad, drooping tails,

till evening, when one puss came down on his own

and set out through the rubble to look for his home.

It was Tiger, poor Tiger, who tried to be bold

as he passed perchless pigeons puffed up with the cold,

and crossed broken bridges pushed up into humps,

the school pool now empty, the field full of lumps.

Over the roundabouts, not fit to ride, he padded past tangles of swings on their sides.

At last, to his street he came, weary and worn - but where was the mailbox? Where was the lawn?
Toda a cidade chacoalhava. Se torcia e se crispava.

Por si sós, os sinos da catedral badalavam. Sem lugar para se esconder nem tempo a perder, Tigre subiu numa árvore que, na praça, não parava de tremer.

Encarapitado em seu topo, ele olhou para baixo...

$\mathrm{E}$, daquele mesmo galho viu, do bairro, quase todos os gatos!

Sob eles, tijolos se desfaziam, chaminés desabavam, lojas desmoronavam!

Sirenes ecoavam - e aos miados, à balburdia, a gataria se juntava.

De manhã, quando o sol nasceu, o mundo olhou consternado para os moradores daquele burgo devastado. $\mathrm{Na}$ árvore, Tigre tiritava de frio. Encontravase desamparado.

Onde estaria Emma naquele amanhecer atribulado?

Temerosos, os gatos amontoados, choravam e miavam. Bigodes baixos e caldas caídas, os mostravam acabrunhados.

Foi assim até o anoitecer quando um deles dali desceu

e, em meio aos escombros, procurar sua casa resolveu.

Era Tigre, o pobre Tigre, afetando coragem ao cruzar por pombos sem ninhos, empertigados de frio, ao transpor pontes empilhadas umas sobre as outras,

Ao passar pela piscina agora vazia da escola, ao atravessar a quadra enrugada, e ao distinguir junto às gangorras inutilizadas, um emaranhado de balanços emborcados. Por fim, cansado e exausto, chegou à sua rua $-$

mas onde estava a sua casa? E o gramado? 
Gone was the place that Tiger called home, and gone was his Emma. He felt so alone. Where could he go and what should he do? He was tired, he was hungry - but then he smelled stew!

He sniffed his way down to the end of the street,

and into a hall through a tangle of feet.

People were queuing, their plates piled high,

Would they give him a morsel - one small bite to try?

Poor Tiger-puss waited ... didn't anyone care?

Then everything changed with the cry,

"Look who's here!

It was Emma! His Emma! He was back home at last, and his horrible day was a thing of the past. His house was in ruins, the whole city battered,

but with Emma's arms round him, none of it mattered.

For a home's not a roof, or a chimney or stairs,

it isn't a cat door or tables and chairs.

Home's not a mailbox, home's not a floor, a home isn't gone with a quake and a roar. Home is a pat and a scratch round the ears, home is a rest from the din and the fears, home is a family, home is a hug, home is a friend and a neighbour's warm rug.

Home is the giving and helping and sharing. When a city is crumbling, then home is the caring.

Home is a lap where it's cosy and warm ... home is where love keeps you safe from the storm.
Pó virara o lugar que Tigre chamara de casa, e Emma, no pó sumira. Ele se sentia tão só. Para onde ir e o que fazer?

Ele estava exausto, ele estava faminto mas, então, farejou comida!

Seguiu o cheiro até o final da rua, e passou sob uma floresta de pernas em um salão.

Viu as pessoas na fila, seus pratos cheios, Dariam a ele um cadinho - só uma pequena porção?

O pobre Tigrezinho esperava ... ninguém se importava?

Então, tudo mudou com um grito, "Olha quem está aqui!"

Era Emma! Sua Emma! Finalmente ele voltara pra casa,

e seu horrível dia passara.

Sim, sua casa estava demolida, a cidade, esfacelada,

mas diante do abraço de Emma, nada disso importava.

Porque casa não é um teto, nem chaminé, nem escadas,

não é uma portinhola para gato ou mesa e bancada.

Casa não é uma fachada, casa não é um chão,

uma casa não desaparece com um sismo e um barulhão.

Casa é um afago e um cafuné no pelo, casa é o descanso do barulho e medos, casa é uma família, casa é um abraço, casa é o cobertor de um amigo ignorado.

Casa é doar-se, ajudar e partilhar.

Em uma cidade arrasada, casa é ter com quem contar.

Casa é um colo quente e acolhedor...

Casa é o amor que protege da dor. 


\section{Referências}

NOONAN, Diane; BISHOP, Gavin (ilustração). Quaky Cat. Nova Zelândia: Scholastic, 2010.

NOONAN, Diane. Quaky Cat. WIATA, Rima T (Narração). Nova Zelândia: Storytime-RNZ, 1 . $^{\circ}$ acesso em 25 de nov. de 2018. Podcast. Disponível em: https://www.radionz.co.nz/collections/storytimetreasure-chest/audio/2516107/quaky-cat-by-diana-noonan. Último acesso em: 15.02.2021.

\section{Sobre o autor}

Rogério Migliorini. Graduado em dança pela UNICAMP (Universidade Estadual de Campinas) e Mestre em Ciências da Religião pela UMESP (Universidade Metodista de São Paulo). Tem experiência nas áreas de dança (direção e atuação) e inglês (ESL e tradução). Pesquisa de modo informal os seguintes temas: consciência corporal; improvisação em dança; diferenças humanas; ritmo e sonoridade do inglês, principalmente do falado na Nova Zelândia e Polinésia. WEBSITE: Den/AMtro: Trespassing of Boundaries and Unification of Differences: https://denamtro.wordpress.com/.

E-mail: awhi63@gmail.com. 